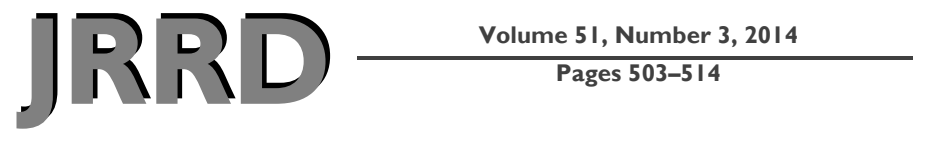

\section{Mixed-method approach to veteran satisfaction with pain education}

\author{
Erin C. Watson, MA; ${ }^{1}$ David Cosio, PhD; ${ }^{2^{*}}$ Erica H. Lin, PharmD ${ }^{3}$ \\ ${ }^{1}$ Psychology Department, Adler School of Professional Psychology, Chicago, IL; Departments of ${ }^{2}$ Anesthesiology and \\ ${ }^{3}$ Pharmacy, Pain Clinic, Jesse Brown Department of Veterans Affairs Medical Center, Chicago, IL
}

\begin{abstract}
Patient education is a central component in highquality integrated care of patients with chronic pain. The current study assessed patients' satisfaction with a $12 \mathrm{wk}$ "Pain Education School" program within the initial $2 \mathrm{yr}$ phase of implementation. A mixed-method treatment outcome design was used. A sample of 219 veterans between November 6, 2009, and January 20, 2012, was evaluated. Quantitative findings suggest that patients reported learning "new and useful" information (mean $=4.62+/-0.82$ ), perceived the program as "easy to understand" ( $4.62+/-0.70)$, used the learned information $(4.58+/-0.77)$, and recommended the program to others $(4.71+/-0.74)$. Four thematic maps emerged from the qualitative data. Response percentages were calculated in order to illustrate the relative magnitude of emerging themes and subthemes corresponding to participant extracts.
\end{abstract}

Key words: chronic pain, health education, integrated care, mixed-method, pain management, patient satisfaction, thematic analyses, themes/subthemes, treatment effectiveness, veterans.

\section{INTRODUCTION}

Despite the complexities of delivering high-quality integrated care, prevailing literature has noted that collaboration between interprofessional practitioners has become increasingly important as efforts to address the medical and psychological needs of patients have expanded [1-8]. More recently, patient education has been recognized as a central component in "high-quality" integrated care, spe- cifically in the care of patients with chronic, noncancer pain [9]. The Joint Commission has mandated that health education programs be implemented to ensure that patients are knowledgeable about treatment options, understand effective use of medication, and are active collaborators in their healthcare needs [10].

There are many examples of successful cross-sector collaborations resulting in improved conditions for patients [2-7]. Problematically, access to effective programs is limited by the referral process and by geographic barriers and is needed given the degree of personal suffering associated with chronic, noncancer pain [5]. One way in which these barriers have been addressed is through the development and implementation of health management programs consisting of education and/or self-management approaches.

Although there has been significant growth in the implementation of chronic pain management programs $[2,11]$, scant research has evaluated the extent to which patient health education programs are deemed satisfactory
Abbreviations: $\mathrm{CAM}=$ complementary and alternative medicine, $\mathrm{CBOC}=$ community-based outpatient clinic, $\mathrm{CBT}=$ cognitive behavioral therapy, PICTEL = picture telephone technology, VA = Department of Veterans Affairs.

*Address all correspondence to David Cosio, PhD; Anesthesiology/Pain Clinic, Jesse Brown VA Medical Center, 820 South Damen Ave \#124, Chicago, IL 60612; 312-5698703; fax: 312-569-8120. Email: david.cosio2@va.gov http://dx.doi.org/10.1682/JRRD.2013.10.0221 
by patients, particularly veterans. Patient satisfaction literature is growing in the areas of surgical and anesthesiology services [12], telehealth [13], general healthcare system performance and service [14-17], and chronic disease and/or prominent medical conditions [12,14]. Patient satisfaction has been associated with better health status, improved engagement in personal healthcare, and reductions in primary care use; conversely, dissatisfaction is commonly associated with disenrollment [13,16-17]. Research in the area of patient satisfaction is likely to lead to improvements in continuity of care [16], particularly in the Department of Veterans Affairs (VA) system.

To address this gap in the literature, the primary objective of the present study was to define and describe patient satisfaction of an empirically validated health education program entitled "Pain Education School" [18-19], which is catered to veterans who experience chronic or persistent noncancer pain. The current mixedmethod research study was designed using Morgan's Priority-Sequence Model as a guide [20]. Quantitative methodology was used to examine the participant-reported satisfaction. Qualitative methodology was employed as a complementary follow-up in order to provide interpretations and explore underlying themes or indicators associated with the reported quantitative satisfaction.

\section{METHODS}

\section{Participants}

Originally, 1,138 veterans were referred to the $12 \mathrm{wk}$ "Pain Education School" program at a Midwestern VA medical center from several different clinics within the facility, including general medicine, mental health, and specialty clinics (pain, orthopedics, and neurology) between November 6, 2009, and January 20, 2012. Approximately 49 percent of referred veterans attended the introduction class of the program. From this target population, a sample of $219(40 \%)$ veterans between 26 and $84 \mathrm{yr}$ old completed the program and the anonymous postintervention satisfaction survey (Figure 1). A recent VA Evidence-Based Synthesis Program report ${ }^{*}$ indicated that group visits focusing on education for the management of chronic conditions in

*Official internal report by VA Evidence-Based Synthesis Program, December 2012.

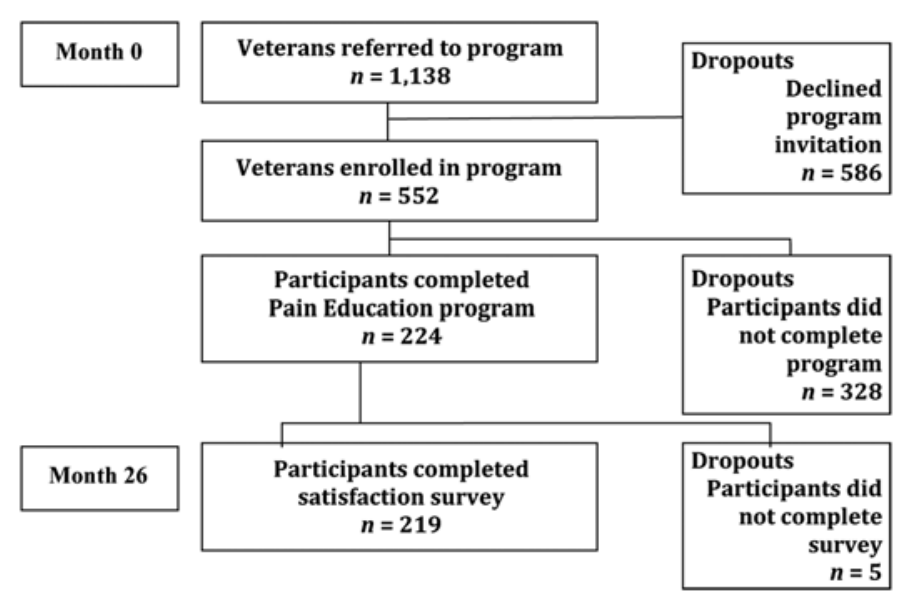

Figure 1.

Flowchart of study participants.

veterans tend to suffer from high levels of attrition, which was substantiated by the current study. The majority of participants were enrolled in a health education program at a Midwestern VA medical center, while some joined from off-site community-based outpatient clinics (CBOCs). The CBOC sites accessed the program via picture telephone technology (PICTEL). Although many rural veterans are in need of pain management education, geographic isolation and physical limitations preclude many from accessing potentially beneficial resources, such as patient pain education. PICTEL-administered interventions constitute a potentially cost-effective way to reach large numbers of rural veterans who cannot access services needed to facilitate their pain management efforts despite any limitations of the technology. Veterans had mixed idiopathic chronic, noncancer pain conditions, including back, neck, limb, head, and fibromyalgia/soft tissue pain. Veterans were referred to the program by any provider who subjectively identified the patient as having (1) failed medical/surgical treatment, (2) exhibited an overreliance on medications/ therapies, (3) displayed pronounced inactivity, (4) experienced significant depression or anxiety related to his/her pain, (5) demonstrated inadequate coping skills, and/or (6) appeared receptive to adopting a self-management approach to pain management. There was no exclusion criteria used for the study. The referring provider submitted a consult in the computerized patient record system, and referred patients were put on a waiting list until the next mandatory introduction class, offered monthly. Each participant was subsequently scheduled for $11 \mathrm{wk}$ of classes 
(12 total including the introduction class). Participants were encouraged to bring family members, spouses, or partners when they attended classes, of which only a few patients tended to invite. At the end of the program, participants received a summary form outlining the referral process for each discipline to review with their primary care provider. Participants voluntarily joined the program and were free to withdraw at any time. Participants were given free parking validation/transportation reimbursement if they were in attendance and were qualified for such programs. The study protocol was reviewed and approved by the affiliated university's institutional review board and the VA's Research $\&$ Development office. No identifiable information was obtained for the purposes of the current study, and a waiver of informed consent was submitted.

\section{Intervention}

Pain Education School is an empirically validated health education program developed at a Midwestern VA medical center in November 2009 catering to veterans with chronic, noncancer pain. The goals of the program are to (1) share basic principles of pain relief and prevention, (2) provide education about pharmacologic interventions, (3) introduce services offering nonpharmacological interventions for relief of noncancer pain, and (4) promote self-management strategies [21]. The program aims to empower patients to self-tailor their own comprehensive pain management plan.

Pain Education School consists of 12 wk of $1 \mathrm{~h}$ classes, with an additional $1 \mathrm{~h}$ introduction class during the first week (total of $13 \mathrm{~h}$ ). Classes are scheduled on a rotating basis regardless of the participant's entry pointthe providers rotate on a schedule, not the participants. Over the course of the program, 22 modules are presented (averaging $30 \mathrm{~min}$ each). The presenters are healthcare providers of the VA that have expertise in the specific module presented. Each module topic is geared toward chronic, noncancer pain management. The modules vary in presentation and may consist of lectures, experiential exercises, and/or discussions. All modules have an audio/visual component and corresponding handouts. The general outline of the modules of the program presented after the introduction class is as follows:

1. Pain Clinic/Osteopathic Manipulation

2. Medication Management

3. Smoking Cessation/Addiction Services

4. Nutrition Services/MOVE! Weight Loss Program

5. Physical Medicine and Rehabilitation
6. Recreation Therapy/Sexual Health

7. Cognitive Behavioral Therapy (CBT)/Acceptance and Commitment Therapy Groups

8. Suicide Prevention and Mental Health/Vocational Rehabilitation

9. Hypnosis/Biofeedback

10. Healing Touch/Spirituality

11. Sleep Clinic/Insomnia CBT Group

12. Acupuncture and Traditional Chinese Medicine

\section{Pain Education-End of School Survey: Opinion/ Satisfaction Survey}

The Opinion/Satisfaction Survey is a quality assurance measure completed by participants at the conclusion of the program. The measure consisted of two components, quantitative and qualitative evaluations. Participants reported satisfaction levels for all 22 interventions presented in the aforementioned 12 modules. All quantitative components were assessed using a 5-point Likert scale ( 1 = "strongly disagree," 5 = "strongly agree"). Participants then rated five evaluative statements assessing the overall effectiveness of the program, including whether participants considered the overall program and its respective disciplines to be "helpful," learned "new and useful" information, believed the program was "easy to understand," used the information that they had learned, and recommended the program to other veterans. Participants were then asked open-ended questions inquiring about the "most important thing(s)" they had learned, suggestions and changes they recommend about any aspect of the program, reasons for absences in their attendance, and what they found "most relevant to themselves and their pain experience."

\section{Analyses of Data}

\section{Priority Sequence Model}

Morgan outlines a sequencing decision process for determining the most applicable research design for complementary combinations of quantitative and qualitative data [20]. Using quantitative methods as the principal approach, the study sought to answer the primary research question, "What components of the program were or were not satisfying to the participants?" Additionally, qualitative methods were used as a complementary follow-up approach to answer the secondary research question, "What indicators or themes are reflective of participant 
satisfaction?" The complementary quantitative and qualitative methods are outlined here.

\section{SPSS}

A quantitative analysis of the data, including descriptive statistics, was realized using the SPSS program (IBM Corporation; Armonk, New York). The primary outcome variables were (1) participants' satisfaction ratings for all 22 interventions and (2) participants' ratings on evaluative statements assessing the overall effectiveness of the program. A power analysis was calculated with an anticipated effect size (Cohen $d$ ) of 0.50 , a desired statistical power level $\geq 0.80$, and a probability level $\leq 0.05$. The minimum total sample size (two-tailed hypothesis) was $n=128$.

\section{Thematic Analysis Approach}

A qualitative analysis of the data obtained in the participant surveys was used as a follow-up complementary method and provided interpretative resources, insights, and explanations [20]. Braun and Clarke's thematic analysis, specifically the inductive semantic approach, compliments the current study's aim to simply organize, show patterns, summarize, and interpret the data [22]. Additionally, the thematic analysis approach clearly outlines a sequential guiding process, is compatible with different paradigms, and gives evidence to unrecognized and underlying data.

Braun and Clarke's six-phase guide was followed in an effort to answer the original research questions [22]. First, two investigators independently familiarized themselves with the data by actively reading through the data, or extracts (i.e., data items), multiple times. Second, the investigators independently searched for potential themes by assessing and organizing data items. At this time, the investigators began to generate potential coding ideas. Third, the investigators independently generated themes by coding the data. Each data extract could be coded as many times as relevant. For example, a data extract that included themes of "coping skills" and "attitude" was included under both themes. Fourth, the investigators met to combine and refine the themes based on their separate generations. Fifth, the themes and subcategories (i.e., subthemes) were finalized and thematic maps were generated to depict a visual representation of the data. The validity of each theme and the accuracy of the thematic map were evaluated in relation to the data set's overarching question related to participant satisfaction. Sixth, content analysis was conducted to calculate the percentages of participants whose statements corresponded to each theme and subtheme [22-23]. Because participants were prompted to respond to multiple openended questions, some overlap exists in the percentage of participants contributing responses to more than one theme/ subtheme.

\section{RESULTS}

The 12 wk Pain Education School program was completed by 224 veterans, of which 219 (98\%) participants were surveyed -5 veterans declined to complete the satisfaction measure. The vast majority of participants attended Pain Education School at the VA medical center (77\%), while 20 percent joined from a $\mathrm{CBOC}$ and 3 percent were unknown. Conclusions about the differences between these two groups could not be delineated since the survey outlined was anonymous, but future exploration is warranted. The participants were overwhelmingly male (82.2\%), while 14.2 percent identified as being female. Of the participants, 65.8 percent identified as African American, while 27.9 percent identified as Caucasian and 2.7 percent as Hispanic/Latino. The most represented age group was 55 to $64 \mathrm{yr}$ old (40.6\%), followed by 45 to $54 \mathrm{yr}$ old $(27.9 \%)$ and 65 to $74 \mathrm{yr}$ old $(12.3 \%)$. The 17 to $24 \mathrm{yr}$ old age group was not represented in the current study. The enrollment rates for the summer start time (28.8\%) was the highest, followed by the winter $(23.3 \%)$. Patient characteristics are summarized in Table 1.

Quantitative findings suggest that participants $(N=$ 219) reported learning "new and useful" information (mean \pm standard deviation $=4.62 \pm 0.82$ ), perceived the program as "easy to understand" (4.62 \pm 0.70$)$, used the learned information $(4.58 \pm 0.77)$, and recommended the program to others $(4.71 \pm 0.74)$, with 95 percent confidence intervals 4.51-4.73, 4.53-4.71, 4.48-4.68, and 4.61-4.81, respectively. See Table 2 for the satisfaction results of each module.

Qualitative findings produced four thematic maps (Figures 2-5). Of the 219 participants, 85 percent commented on "the most important thing(s) learned." Six major themes emerged in this area: coping skills (41\%), available support (34\%), specific modules (18\%), medication (13\%), attitude (12\%), and the mind-body relationship 
Table 1.

Description of participants. Total $N=219$.

\begin{tabular}{lc}
\hline \multicolumn{1}{c}{ Characteristic } & $\boldsymbol{n}(\mathbf{\%})$ \\
\hline Sex & $180(82.2)$ \\
Male & $31(14.2)$ \\
Female & $8(3.6)$ \\
Unknown & \\
Identified Race & $144(65.8)$ \\
African American & $61(27.9)$ \\
White & $6(2.7)$ \\
Hispanic & $8(3.6)$ \\
Unknown & \\
Location of Class & $169(77.2)$ \\
JBVA & $6(2.7)$ \\
CBOC 1 & $38(17.4)$ \\
CBOC 2 & $6(2.7)$ \\
Unknown & \\
Start Month & $50(22.8)$ \\
Fall: September-November & $51(23.3)$ \\
Winter: December-February & $49(22.4)$ \\
Spring: March-May & $63(28.8)$ \\
Summer: June-August & $6(2.7)$ \\
Unknown & \\
Age Group (yr) & $10(4.7)$ \\
17-24 & $61(8.2)$ \\
25-34 & $89(40.6)$ \\
35-44 & $6(2.7)$ \\
45-54 & \\
55-64 & \\
65-74 & \\
75+ & \\
Unknown & \\
of Veterans Affairs Medical Center. & \\
\hline \hline
\end{tabular}

(3\%). While all themes were commented on, the most frequently mentioned subtheme was the learning or demonstration of cognitive coping skills (26\%), followed by available support as an option or alternative (14\%) and general support (14\%). See Tables 3 through 6 for extracts corresponding with each theme and subtheme.

Of the participants, 77 percent commented on the statement, "If I could change anything." Six major themes emerged in this area: no changes (51\%), structural mechanics $(30 \%)$, specific modules $(22 \%)$, ground rules $(9 \%)$, technology $(4 \%)$, and barriers $(2 \%)$. Most relevant subthemes included making no changes, as indicated by participants commenting "nothing" (44\%), and making
Table 2.

Participant satisfaction of pain education school modules.

\begin{tabular}{|c|c|c|c|}
\hline \multirow{2}{*}{ Module } & \multirow{2}{*}{ Mean \pm SD } & \multicolumn{2}{|c|}{$95 \% \mathrm{CI}$} \\
\hline & & $\mathbf{L L}$ & UL \\
\hline Introductory Class & $4.42 \pm 0.92$ & 4.29 & 4.54 \\
\hline Pain Clinic & $4.46 \pm 0.88$ & 4.34 & 4.58 \\
\hline Osteopathic Manipulation & $4.29 \pm 0.82$ & 4.18 & 4.40 \\
\hline Medical Management & $4.31 \pm 0.86$ & 4.19 & 4.43 \\
\hline Smoking Cessation & $3.95 \pm 1.19$ & 3.78 & 4.12 \\
\hline Addiction Services & $4.08 \pm 1.15$ & 3.92 & 4.24 \\
\hline Nutrition Services & $4.32 \pm 0.88$ & 4.20 & 4.44 \\
\hline MOVE! Program & $4.24 \pm 0.97$ & 4.11 & 4.37 \\
\hline $\begin{array}{l}\text { Physical Medicine \& } \\
\text { Rehabilitation }\end{array}$ & $4.13 \pm 1.07$ & 3.98 & 4.28 \\
\hline Recreation Therapy & $4.27 \pm 0.97$ & 4.13 & 4.41 \\
\hline Sexual Health & $4.09 \pm 1.12$ & 3.93 & 4.24 \\
\hline Pain CBT Group & $4.23 \pm 0.96$ & 4.09 & 4.37 \\
\hline Pain ACT Group & $4.29 \pm 0.91$ & 4.16 & 4.42 \\
\hline $\begin{array}{l}\text { Psychiatric Assessment } \\
\text { Clinic }\end{array}$ & $4.12 \pm 1.03$ & 3.96 & 4.28 \\
\hline Suicide Prevention Program & $4.14 \pm 1.08$ & 3.98 & 4.30 \\
\hline Hypnosis & $3.92 \pm 1.23$ & 3.75 & 4.09 \\
\hline Biofeedback & $4.15 \pm 1.07$ & 4.00 & 4.30 \\
\hline Healing Touch & $4.11 \pm 1.08$ & 4.00 & 4.26 \\
\hline Spirituality & $4.18 \pm 1.14$ & 4.02 & 4.34 \\
\hline Sleep Clinic & $4.19 \pm 1.02$ & 4.05 & 4.33 \\
\hline Insomnia Group & $4.10 \pm 1.02$ & 4.00 & 4.24 \\
\hline $\begin{array}{l}\text { Acupuncture/Traditional } \\
\text { Chinese Medicine }\end{array}$ & $4.21 \pm 1.10$ & 4.06 & 4.36 \\
\hline
\end{tabular}

changes to the time/date/length of the program (17\%). Participants overwhelmingly asked for the program to be extended so that more information could be learned.

Of the participants, 81 percent commented on "most relevant for you and your pain experience." Six major themes emerged in this area: modules (15\%), available support (10\%), medication (9\%), coping skills (8\%), attitude (3\%), and the mind-body relationship (3\%). Specific modules most relevant to participants included acupuncture and medication management. Of the 53 participants polled, 72 percent commented on the barriers to attendance. Four major themes emerged in this area: travel (24\%), no barriers (24\%), financial (21\%), and illness (18\%). Most relevant subthemes following "no barriers" included specific financial concerns (16\%) and medical illness $(13 \%)$. 
JRRD, Volume 51, Number 3, 2014

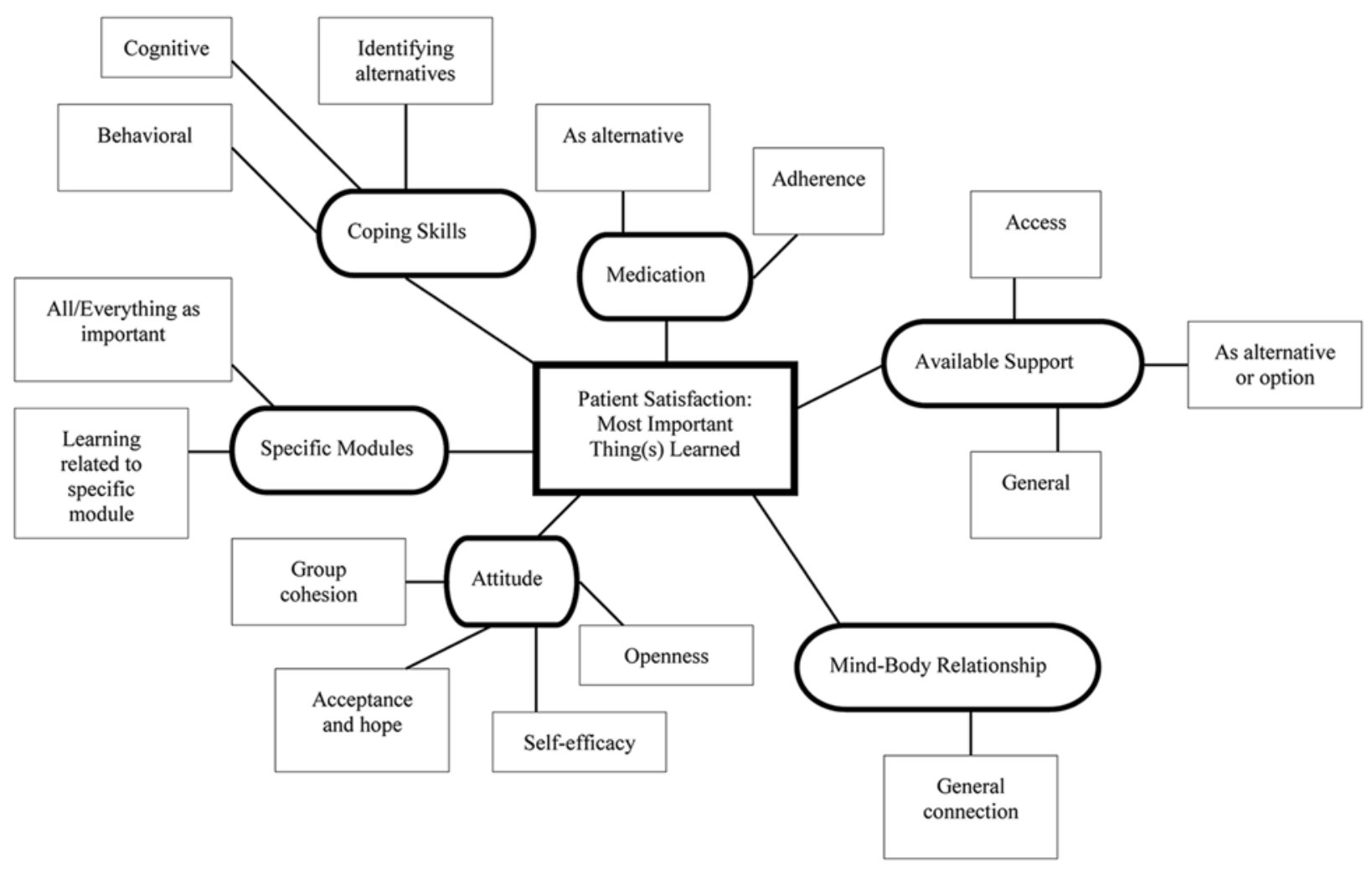

Figure 2.

Patient satisfaction: Most important thing(s) learned.

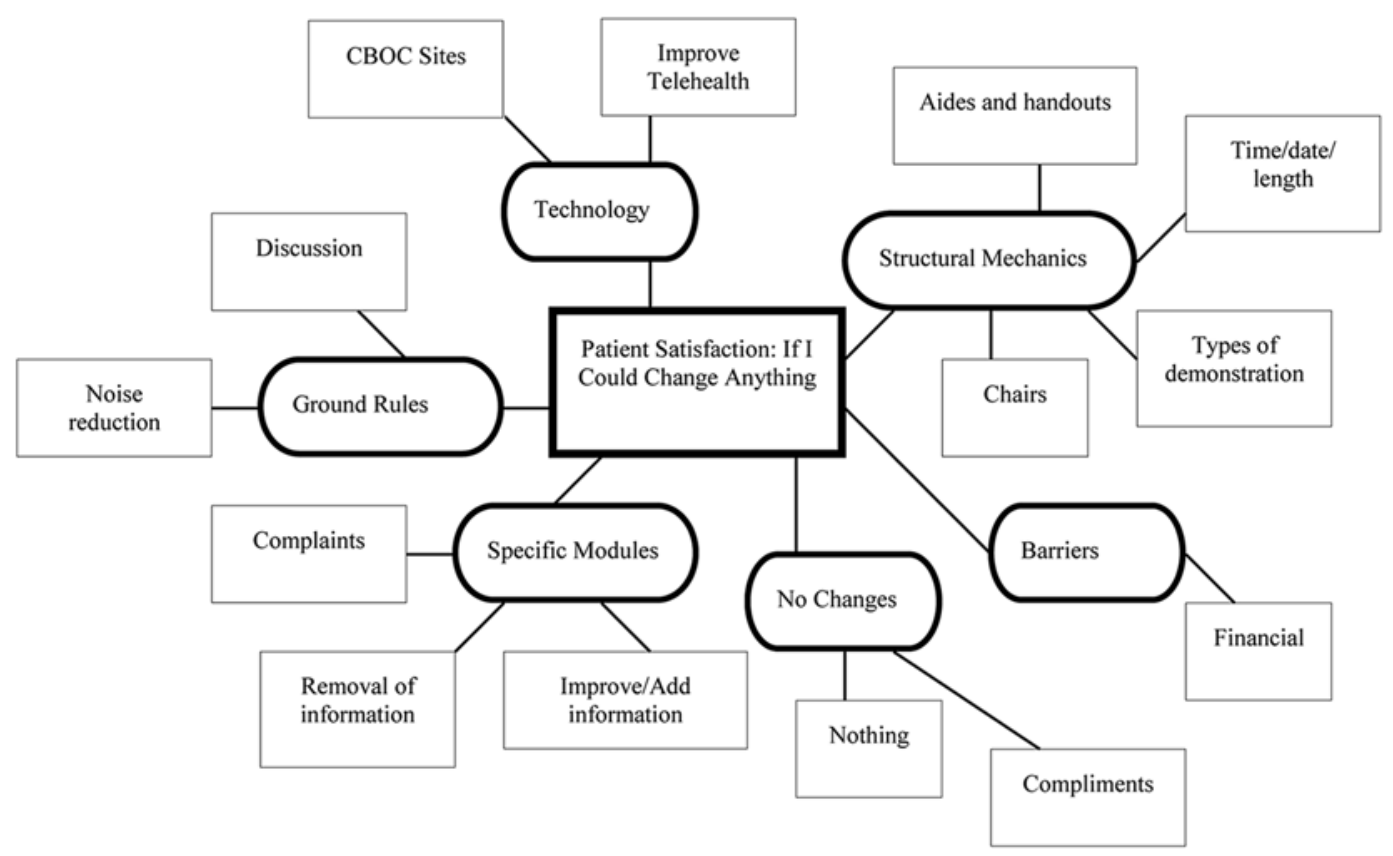

Figure 3.

Patient satisfaction: If I could change anything. $\mathrm{CBOC}=$ Community-based outpatient clinic. 


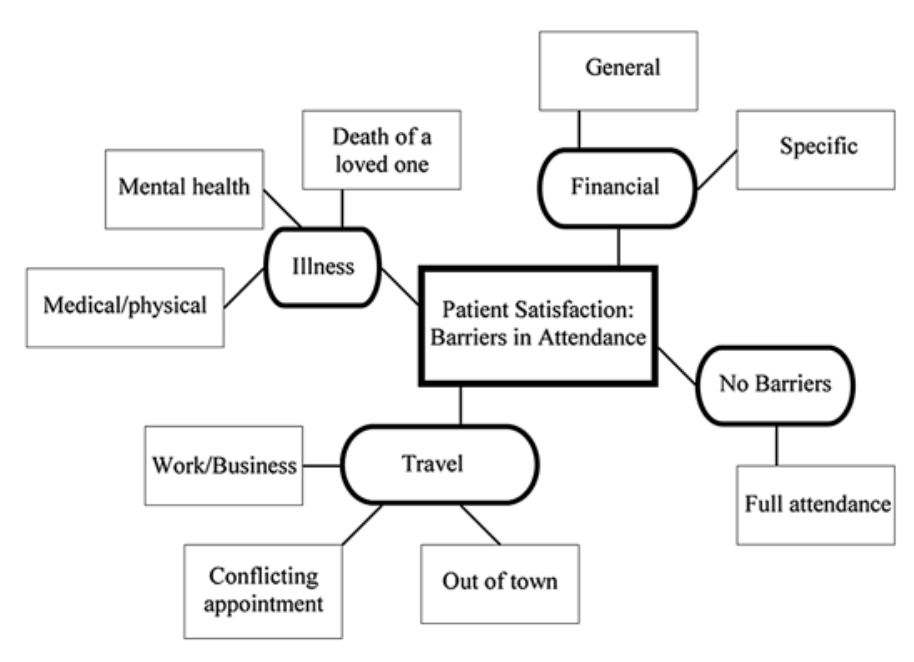

Figure 4.

Patient satisfaction: Barriers in attendance.

\section{DISCUSSION}

The current study allowed for the identification of key treatment elements from the patient's perspective, having both practical and theoretical implications in furthering the development and implementation of health education programs for chronic pain. This comprehensive patient-centered approach is particularly important when determining satisfaction. The current study also provided a fuller investigation of satisfaction often inaccessible through traditional quantitative methods by using a multimethod approach [23-24].

The findings from the patient satisfaction survey revealed overall effectiveness of the program in terms of the usefulness of knowledge disseminated, ease in comprehension, application of lessons learned, and likelihood of future recommendation of the program to others. The overall findings are consistent with past literature, which suggests that patients rate satisfaction with medical care highly when employing Likert-scale measures [15]. The findings indicated overall patient satisfaction for all 22 interventions. Quantitative results revealed the initial introductory module and the pain clinic module were the most satisfying. This finding may suggest many patients were unaware of the many other available modalities offered at the VA and the comprehensive treatment approach to chronic pain management presented in the introduction class. The modules related to tobacco cessation and hypnosis were the least satisfactory of the 22 modules. Participant extracts confirm that patients who did not smoke felt as if they should not have to attend this particular module. Participants' less than satisfactory view of hypnosis also depended on how applicable the modality was to their personal pain experience (such as cultural beliefs) and/or external factors such as the provider(s) who facilitated the lecture. Past literature has hypothesized that attention or concern of a provider has been shown to be associated with satisfaction $[6,12]$.

Participant extracts revealed cognitive skills as the most important thing learned. Patients demonstrated cognitive learning by using language related to coping with their chronic pain condition as seen in the extracts. This finding represents an important shift in pain management since literature calls for a bio-psycho-social-spiritual approach, rather than biomedical, in managing chronic pain [25]. Interestingly, patients most often cited the acupuncture and medication management modules as the most relevant to their pain experience, as noted in the extracts. The findings related to medication management were expected, considering the management of acute and at times chronic pain conditions is often biomedical in focus. Conversely, an endorsement of acupuncture suggests these patients may also be open-minded to complementary and alternative medicine (CAM). These findings are similar to prior literature that suggests older adults with chronic pain are more likely to benefit from alternative treatments because these patients have often already tried the conventional treatment options [6]. Past research has also found that minorities report higher pain levels than Caucasians and resultantly, individuals with higher average daily pain reported using more CAM [26]. Collectively, these results are consistent with past findings that suggest patients are not fully aware of available pain relief options [12] and are open to alternative treatment options. The VA healthcare system has moved toward making certain CAM treatment options available as research supports their utility and reveals what options veterans are willing to try [27]. Future studies may want to explore the utilization and knowledge of CAM modalities among veterans with chronic or persistent noncancer pain.

More than half of the participants stated that they would not change the program in any way. About onethird of patients suggested the program be longer, more comprehensive, and extended for additional questions and discussion, as seen in the extracts. This finding is particularly perplexing because past literature often highlights the need for succinct programs that deliver medical information in a timely fashion [13], perhaps because of 
JRRD, Volume 51, Number 3, 2014

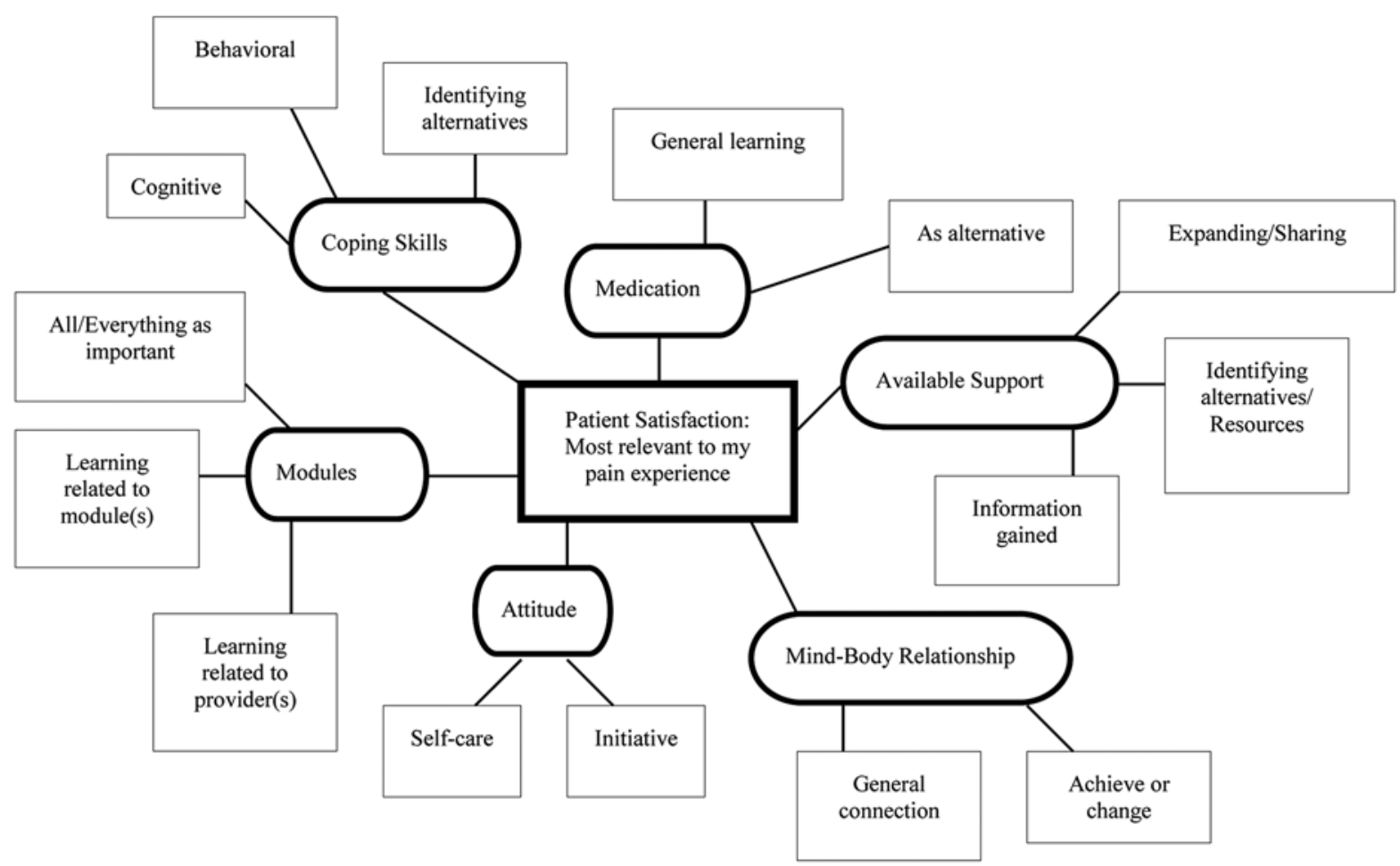

Figure 5.

Patient satisfaction: Most relevant to my pain experience.

Table 3.

Patient satisfaction: Most important thing(s) learned.

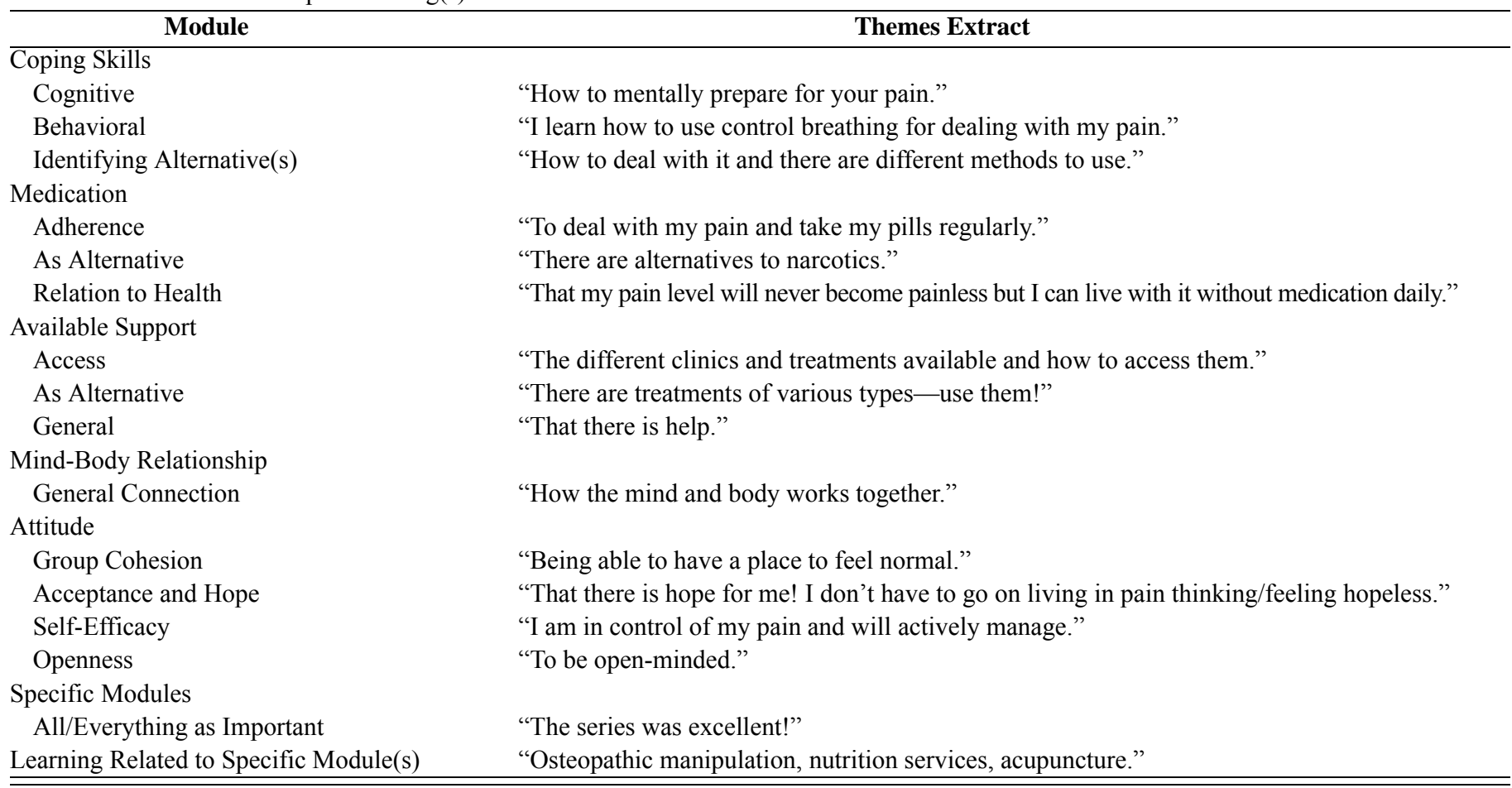


Table 4.

Patient satisfaction: If I could change anything.

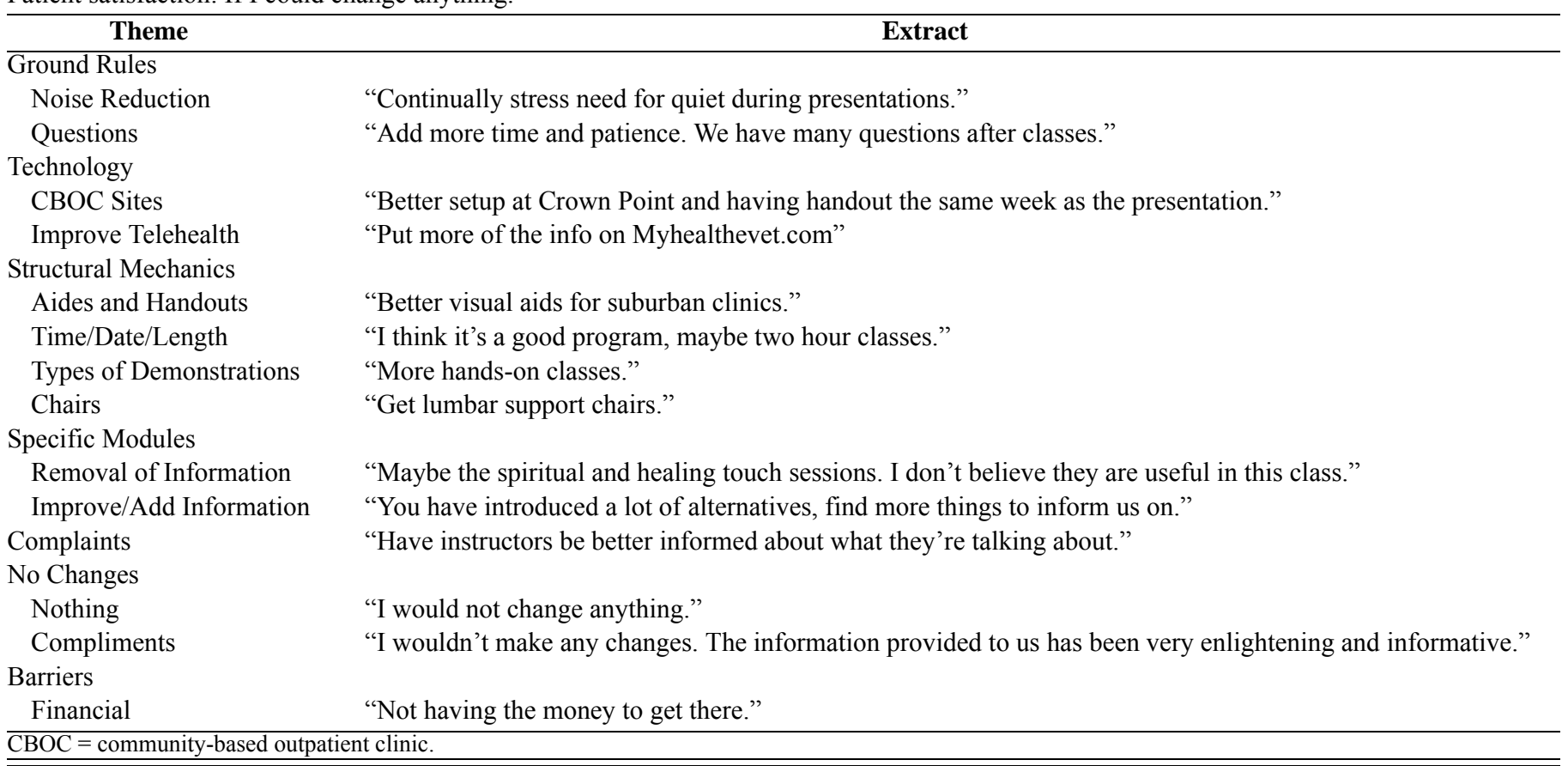

Table 5.

Patient satisfaction: Barriers in attendance.

\begin{tabular}{|c|c|}
\hline Theme & Extract \\
\hline \multicolumn{2}{|l|}{ Illness } \\
\hline Medical/Physical & "Two sessions missed due to illness." \\
\hline Mental Health & $\begin{array}{l}\text { "Hospitalizations for depression and suicide } \\
\text { attempts." }\end{array}$ \\
\hline Death of a Loved One & "Death in the family." \\
\hline \multicolumn{2}{|l|}{ Travel } \\
\hline Work/Business & "Work." \\
\hline Conflicting Appointment & $\begin{array}{l}\text { "Having other appointment with other } \\
\text { clinic." }\end{array}$ \\
\hline Out of Town & "... Two because I had to go out of town." \\
\hline Transportation Issues & "Only because I had car trouble." \\
\hline \multicolumn{2}{|l|}{ Financial } \\
\hline General & "Not having the money to get there." \\
\hline Specific & "Housing. I am a homeless vet." \\
\hline \multicolumn{2}{|l|}{ No Barriers } \\
\hline Full Attendance & "Attended all 12 classes." \\
\hline
\end{tabular}

chronic pain conditions interfering with patients' ability to sit for long periods of time. Similarly, patients asked for their weekly handouts to have more information on them. These findings are consistent with prior literature suggesting that the amount of education learned $[6,12]$ and the practice setting (i.e., organization model) [28] are directly related to patient satisfaction.
Patient satisfaction indicators less often mentioned were related to attitude, medication, and instructional aids. Many patients cited no change in pain status but spoke to "acceptance," as seen in the extracts. Similarly, many patients spoke to medication as an alternative rather than the sole option and also spoke to the importance for adherence. This key finding validates literature calling for comprehensive pain management approaches [7-8,25,29-30]. Additionally, patients generally asked for a reduction in verbal learning (e.g., didactic lecture) and an increase in visual activities (e.g., demonstrations) and process/discussion. These results are consistent with prior research that suggests that both education and selfmanagement skills are crucial aspects of health education programs [2-4,6-7,30]. Self-management involves building confidence to perform disease, role, and emotional management of the patient's illness in partnership with his or her healthcare providers [31].

A strength of this study is the multimethod "priority sequence model" and the broad referral base. Overall, the quantitative results of this study suggested satisfaction. Additionally, the qualitative data allowed for delineation among specific satisfaction modules and structural and aesthetic (e.g., seating arrangements) aspects of the program. Participants are interested in learning more and sharing what they have learned with others, and are feeling better. 
JRRD, Volume 51, Number 3, 2014

Table 6.

Patient satisfaction: Most relevant to my pain experience.

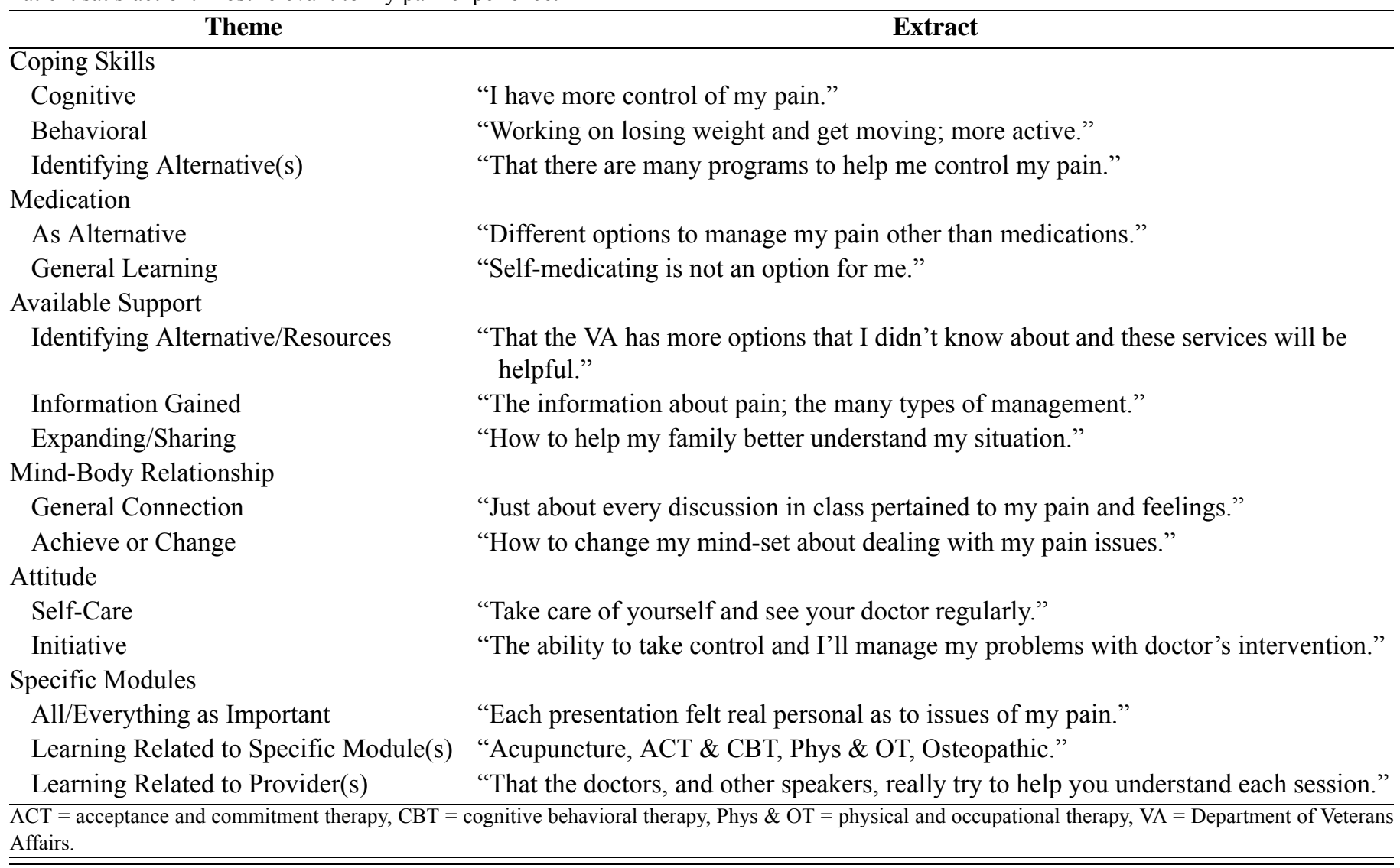

Still, there are some notable opportunities to improve patient satisfaction with the efficacy of this school (i.e., comfort of seating, more detailed handouts, and more time for discussion) that can be implemented at the VA medical center. Relationships with support staff need to be strengthened in order to improve these areas and more consistently incorporate them into the program. Accomplishment of these tasks may require revision of the patient education materials, increased communication with the facilitating providers and hospital staff, and expanding resources. Educating providers and patients about the satisfaction of the program may prompt providers to consider referring more patients to the clinic and, moreover, more closely attend to their patients' chronic pain needs.

\section{LIMITATIONS}

There are several noteworthy limitations of this study that may restrict the generalizability of the study's find- ings. First, not all the patients discharged during the study period attended all 13 classes of the program or completed the postmeasures. Second, the instrument used in this study is a self-report measure that may be vulnerable to acquiescence biased reporting [15]. Third, the current sample was overrepresentative of African-American male veterans between the ages of 55 and 64 yr. Finally, the time constraints for implementation of the program includes hourly modules that may be a less than the ideal amount of time for veterans to digest complex health education material given that prevailing literature suggests more time for complex processing [10,32]. Providers from participating disciplines may need to find ways to overcome barriers in developing low-literacy materials (e.g., government publications process) [32-33]. Again, space availability, room scheduling, and the time providers volunteer to facilitate a module present barriers to expanding the program. Most importantly, provider satisfaction should be collected in future patient-centered evaluations to enhance the overall understanding of satisfaction. 


\section{CONCLUSIONS}

The current study is the first known investigation to examine patient satisfaction of an empirically validated health education program catered to veterans who experience chronic or persistent noncancer pain. It differs from previous studies in that it (1) used a mixed-methods treatment outcome design; (2) combined education, selfmanagement, and technology components; and (3) focused specifically on veteran patients with mixed idiopathic chronic pain conditions, thus providing a novel way this study contributes to the existing body of literature. This information is invaluable to help providers improve the existing program for current and future participants who share the same or similar condition and for the providers aiding in the facilitation of the program.

\section{ACKNOWLEDGMENTS}

\author{
Author Contributions: \\ Study concept and design: D. Cosio, E. C. Watson. \\ Acquisition of data: D. Cosio, E. H. Lin, E. C. Watson. \\ Analysis and interpretation of data: D. Cosio, E. C. Watson. \\ Drafting of manuscript: E.C. Watson, D. Cosio. \\ Critical revision of manuscript for important intellectual content: \\ D. Cosio, E. H. Lin, E. C. Watson.
}

Financial Disclosures: The authors have declared that no competing interests exist.

Funding/Support: This material was unfunded at the time of manuscript preparation.

Additional Contributions: The authors thank all the veterans and providers who made this research possible. The authors would also like to thank the Jesse Brown VA Medical Center, Anesthesiology/ Pain Clinic department for their vision and ongoing support of the "Pain Education School" program. Ms. Watson is currently completing her psychology internship at the Portland VA Medical Center, Portland, Oregon.

Institutional Review: The study protocol was reviewed and approved by the affiliated university's institutional review board and the VA's Research \& Development office. No identifiable information was obtained for the purposes of the current study and a waiver of informed consent was submitted.

Participant Follow-Up: Participants will learn about study results through the VA Research Fair and publication of the article.

\section{REFERENCES}

1. Flor H, Fydrich T, Turk DC. Efficacy of multidisciplinary pain treatment centers: A meta-analytic review. Pain. 1992;49(2):221-30. [PMID:1535122] http://dx.doi.org/10.1016/0304-3959(92)90145-2
2. LeFort SM, Gray-Donald K, Rowat KM, Jeans ME. Randomized controlled trial of a community-based psychoeducation program for the self-management of chronic pain. Pain. 1998;74(2-3):297-306. [PMID:9520244] http://dx.doi.org/10.1016/S0304-3959(97)00190-5

3. Lorig KR, Ritter P, Stewart AL, Sobel DS, Brown BW Jr, Bandura A, González VM, Laurent DD, Holman HR. Chronic disease self-management program: 2-year health status and health care utilization outcomes. Med Care. 2001;39(11):1217-23. [PMID:11606875] http://dx.doi.org/10.1097/00005650-200111000-00008

4. Lorig KR, Sobel DS, Ritter PL, Laurent D, Hobbs M. Effect of a self-management program on patients with chronic disease. Eff Clin Pract. 2001;4(6):256-62. [PMID:11769298]

5. Lorig KR, Sobel DS, Stewart AL, Brown BW Jr, Bandura A, Ritter P, Gonzalez VM, Laurent DD, Holman HR. Evidence suggesting that a chronic disease self-management program can improve health status while reducing hospitalization: A randomized trial. Med Care. 1999;37(1):5-14.

[PMID:10413387] http://dx.doi.org/10.1097/00005650-199901000-00003

6. Morone NE, Rollman BL, Moore CG, Li Q, Weiner DK. A mind-body program for older adults with chronic low back pain: Results of a pilot study. Pain Med. 2009;10(8): 1395-1407. [PMID:20021599] http://dx.doi.org/10.1111/j.1526-4637.2009.00746.x

7. Pape DA, Rafiullah M. The collaborative role of the psychologist and physician on an interdisciplinary pain rehabilitation team. Clin Case Stud. 2005;4(2):205-22. http://dx.doi.org/10.1177/1534650103259769

8. Turk DC, Okifuji A. Psychological factors in chronic pain: Evolution and revolution. J Consult Clin Psychol. 2002; 70(3):678-90. [PMID:12090376] http://dx.doi.org/10.1037/0022-006X.70.3.678

9. Institute of Medicine. Relieving pain in America: A blueprint for transforming prevention, care, education, and research [Internet]. Washington (DC): Institute of Medicine; 2011 Jun 29 [cited 2011 Nov 2]. Available from: http://www.iom.edu/Reports/2011/Relieving-Pain-inAmerica-A-Blueprint-for-Transforming-Prevention-CareEducation-Research.aspx

10. Behar-Horenstein LS, Guin P, Gamble K, Hurlock G, Leclear E, Philipose M, Shellnut D, Ward M, Weldon J. Improving patient care through patient-family education programs. Hosp Top. 2005;83(1):21-27. [PMID:16092635] http://dx.doi.org/10.3200/HTPS.83.1.21-27

11. Siminerio L. Defining the role of the health education specialist in the United States. Diabetes Spectr. 1999;12(3):152-57.

12. Sauaia A, Min SJ, Leber C, Erbacher K, Abrams F, Fink R. Postoperative pain management in elderly patients: Correlation between adherence to treatment guidelines and patient satisfaction. J Am Geriatr Soc. 2005;53(2):274-82. [PMID:15673352] http://dx.doi.org/10.1111/j.1532-5415.2005.53114.x 
13. LaVela SL, Gering J, Schectman G, Weaver FM. Optimizing primary care telephone access and patient satisfaction. Eval Health Prof. 2012;35(1):77-86. [PMID:21685222] http://dx.doi.org/10.1177/0163278711411479

14. Collins C, Kramer A, O’Day ME, Low MB. Evaluation of patient and provider satisfaction with a pharmacistmanaged lipid clinic in a Veterans Affairs medical center. Am J Health Syst Pharm. 2006;63(18):1723-27. [PMID:16960256] http://dx.doi.org/10.2146/ajhp060098

15. Kurata JH, Nogawa AN, Phillips DM, Hoffman S, Werblun MN. Patient and provider satisfaction with medical care. J Fam Pract. 1992;35(2):176-79. [PMID:1645110]

16. Stroupe KT, Hynes DM, Giobbie-Hurder A, Oddone EZ, Weinberger M, Reda DJ, Henderson WG. Patient satisfaction and use of Veterans Affairs versus non-Veterans Affairs healthcare services by veterans. Med Care. 2005; 43(5):453-60. [PMID:15838409] http://dx.doi.org/10.1097/01.mlr.0000160377.82164.d3

17. Zapka JG, Palmer RH, Hargraves JL, Nerenz D, Frazier HS, Warner CK. Relationships of patient satisfaction with experience of system performance and health status. J Ambul Care Manage. 1995;18(1):73-83. [PMID:10139348] http://dx.doi.org/10.1097/00004479-199501000-00008

18. Cosio D, Hugo E, Roberts S, Schaefer D. A pain education school for veterans: Putting prevention into VA practice. Fed Pract. 2012;29(3):23-29.

19. Cosio D, Lin E. Effects of a pain education program for veterans with chronic, noncancer pain: A pilot study. J Pain Palliat Care Pharmacother. 2013;27(4):340-49. [PMID:24147960] http://dx.doi.org/10.3109/15360288.2013.846953

20. Morgan DL. Practical strategies for combining qualitative and quantitative methods: Applications to health research. Qual Health Res. 1998;8(3):362-76. [PMID:10558337] http://dx.doi.org/10.1177/104973239800800307

21. Ferrell BR, Rhiner M, Ferrell BA. Development and implementation of a pain education program. Cancer. 1993; 72(11 Suppl):3426-32. [PMID:8242574]

22. Braun V, Clarke V. Using thematic analysis in psychology. Qual Res Psychol. 2006;3(2):77-101. http://dx.doi.org/10.1191/1478088706qp063oa

23. Day MA, Thorn BE, Kapoor S. A qualitative analysis of a randomized controlled trial comparing a cognitive-behavioral treatment with education. J Pain. 2011;12(9):941-52. [PMID:21839689] http://dx.doi.org/10.1016/j.jpain.2011.02.354

24. Patton MQ. Qualitative research and evaluation methods, 3rd ed. Thousand Oaks (CA): Sage Publications; 2002.

25. Crowley-Matoka M, Saha S, Dobscha SK, Burgess DJ. Problems of quality and equity in pain management: Exploring the role of biomedical culture. Pain Med. 2009; 10(7):1312-24. [PMID:19818041] http://dx.doi.org/10.1111/j.1526-4637.2009.00716.x
26. Meghani SH, Cho E. Self-reported pain and utilization of pain treatment between minorities and nonminorities in the United States. Public Health Nurs. 2009;26(4):307-16. [PMID:19573209] http://dx.doi.org/10.1111/j.1525-1446.2009.00785.x

27. Denneson LM, Corson K, Dobscha SK. Complementary and alternative medicine use among veterans with chronic noncancer pain. J Rehabil Res Dev. 2011;48(9):1119-28. [PMID:22234716] http://dx.doi.org/10.1682/JRRD.2010.12.0243

28. Haas JS, Cook EF, Puopolo AL, Burstin HR, Cleary PD, Brennan TA. Is the professional satisfaction of general internists associated with patient satisfaction? J Gen Intern Med. 2000;15(2):122-28. [PMID:10672116] http://dx.doi.org/10.1046/j.1525-1497.2000.02219.x

29. Irajpour A, Norman I, Griffiths P. Interprofessional education to improve pain management. Br J Community Nurs. 2006;11(1):29-32. [PMID:16493295]

30. MacDonald NE, Flegel K, Hébert PC, Stanbrook MB. Better management of chronic pain care for all. CMAJ. 2011; 183(16):1815. [PMID:21844104] http://dx.doi.org/10.1503/cmaj.111065

31. Lorig KR, Holman HR. Self-management education: history, definition, outcomes, and mechanisms. Ann Behav Med. 2003;26(1):1-7. [PMID:12867348] http://dx.doi.org/10.1207/S15324796ABM2601 01

32. Friedman DB, Goetz LH. Literacy and health literacy as defined in cancer education research: A systematic review. Health Educ J. 2008;67(4):285-304. http://dx.doi.org/10.1177/0017896908097071

33. Karp JF, Reynolds CF 3rd, Butters MA, Dew MA, Mazumdar S, Begley AE, Lenze E, Weiner DK. The relationship between pain and mental flexibility in older adult pain clinic patients. Pain Med. 2006;7(5):444-52. [PMID:17014605] http://dx.doi.org/10.1111/j.1526-4637.2006.00212.x

Submitted for publication October 16, 2013. Accepted October 30, 2013.

This article and any supplementary material should be cited as follows:

Watson EC, Cosio D, Lin EH. Mixed-method approach to veteran satisfaction with pain education. J Rehabil Res Dev. 2014;51(3):503-14. http://dx.doi.org/10.1682/JRRD.2013.10.0221

ResearcherID/ORCID: David Cosio, PhD: E-4361-2014

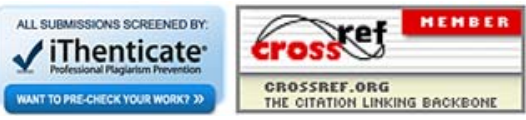

